\title{
Patient Data Secrecy using Apriori with a Posteriori Anonymization
}

\author{
Madhavilatha Pandala, Madhavi Katamaneni, Praveena Nutakki
}

\begin{abstract}
A multilingual terminology for discussing safety by information minimization such as namelessness, unlink potential, imperceptibility, inconspicuousness, pseudonymity, and character the executives can be located in $[1,4,6]$. An account or observational informational index is known as microdata. Each recording or notion has plenty of factors. This association of factors should be classified and might must be modified a good way to observe protection saving information dispensing measures. Microdata is required to be blanketed whilst its conscious or incidental revelation would not do any mischief to the population in query. Preset programming settings for ok threat levels might be set by legitimate conditions to be legal as open use files or microdata records underneath agreement for have a look at functions. As a marker of the present state of affairs, facts secured by HIPAA and Safe Harbor suggestions bring about a re-recognizable evidence chance proportion of round zero.04\% (this is $4 / 10.000$ ), going between $0.01 \%$ to $0.25 \%$ and being $10 \%$ to $60 \%$ if there need to be an incidence of limited informational collections beneath non-revelation understandings agreeing to[8]. Further trial estimations can be located.
\end{abstract}

Keywords: Microdata, privacy preserving, identity management, anonymity.

\section{INTRODUCTION}

Numerous institutions that take care of touchy records are thinking about utilising disbursed computing because it offers belongings that may be scaled correctly, alongside essential monetary blessings as diminished operational prices. Notwithstanding, it very well can be muddled to efficaciously deal with sensitive records in allotted computing conditions because of the scope of safety enactment and guidelines that exist. A few instances of such enactment are the European Union (EU) Data Protection Directive (DPD) [8] and the USA Health Insurance Portability and Accountability Act (HIPAA) [9], each interest security conservation for looking after by means of and by means of recognizable facts. This proposition examines the problems looked via such institutions and portrays how disbursed computing can be utilized to offer creative preparations that assure the safety of

Revised Manuscript Received on April 13, 2020.

* Correspondence Author

P.Madhavilatha*, Department of IT, VRSEC, Vijayawada, India. Email: chinnu065@gmail.com

K.Madhavi, Department of IT, VRSEC, Vijayawada, India. Email: itsmadhavi12@gmail.com

Geetha.G, Department of IT, VRSEC, Vijayawada, India. Email: geetaguttikonda@gmail.com

(C) The Authors. Published by Blue Eyes Intelligence Engineering and Sciences Publication (BEIESP). This is an open access article under the CC BY-NC-ND license (http://creativecommons.org/licenses/by-nc-nd/4.0/) sensitive data. The principle focal point of this proposition is on protection and protection issues concerning data created by means of clinical research, which calls for in particular extreme protection saving arrangements [10]. For instance, an analyst that appears to recognize the human body and addition bits of understanding into infection paperwork with the aid of the use of large information investigation and dispensed computing innovations. Nonetheless, while using records within the cloud, its miles important to consider the ethical and administrative contemplations that perceive with data ownership.

Such information need to be prepared straightforwardly with the purpose that the personalities of those who "declare" the records are not uncovered. Therefore, cloud-based totally preparations need to ensure statistics security in a suitable manner. In the meantime, a fantastic a part of the current protection enactment impedes medical institutions from utilizing cloud administrations - incompletely due to the way information the board jobs for scientific information are characterized at present and moreover because of barriers forced with the aid of the existing principles for overseeing medical records.

Quite a while classification safety manner is to weaken statistics by corrupting the accuracy of given data statistics in a managed method, so the database can even now satisfy the proposed purpose, however isn't sufficiently express to keep in mind simple re-distinguishing proof. This take a look at may be communicated as an undertaking of overseeing re-distinguishing proof dangers, in view of the recognizing stage of the homes while mulling over the foundation statistics reachable. The method relies upon on an iterative development technique without giving tough guarantees, reflecting risk the executives in specific elements of life, as an example, being hit through a mishap.

To deliver secure microdata, factors are looked after into at any fee three, now not absolutely particular gatherings: elements that are expressly and straightforwardly distinguishing, as an instance, man or woman numbers, government controlled financial savings numbers, sequential numbers and so on. Key factors (moreover known as pseudo keys, QID or non-sensitive homes) are a meeting of factors which are distinguishing while utilized collectively. Connecting depending on key elements is applied when chronicled information are dealt with that don't have any unequivocal identifiers, e.G., [1-5] or whilst connecting assaults are done, for instance, [4-16] with the give up intention of re-distinguishing evidence. Picking is frequently based on required things set out via regulation (EU DPD [8], HIPAA [9] and such) or by dealing with the hazard of being fined $[6,7]$.

\section{Published By:}

Blue Eyes Intelligence Engineering \& Sciences Publication

(C) Convriaht: All riahts reserved. 
Also, to wrap things up, by means of using sound judgment: as a dependable guideline, non-sensitive residences are the ones which are in all likelihood going to expose up in exclusive databases, regardless of whether brazenly available or no longer, alongside these lines, which can in all likelihood be applied for connecting.

A common model is a reputedly innocent sexual orientation, date of beginning and ZIP code triplet which is profoundly distinguishing to maximum of a populace and may be determined in limitless databases. Remaining elements (likewise referred to as delicate or non-secret elements) that aren't within the gatherings referenced formerly. They are either not anticipated to reveal up in a few different database and, in the end, cannot be applied for connecting or are not distinguishing generally.

Preset programming settings for nice danger levels might be set via lawful requirements to be legal as open use information or microdata files under agreement for discover functions. As a pointer of the present scenario, facts ensured by HIPAA and Safe Harbor hints result in a re-recognizable proof threat percentage of round zero.04\% (that is $4 / 10.000$ ), extending among $0.01 \%$ to zero. $25 \%$ and being $10 \%$ to $60 \%$ if there must be an occurrence of restricted informational indexes under non-divulgence understandings agreeing to[8]. Further trial estimations may be determined.

There are many existing toolboxes to assist produce secure microdata, giving often utilized anonymization calculations, for instance, okay-secrecy [6-8] and '- first rate variety [7]. Argus [10], sdcMicro [11], and University of Texas at Dallas (UTD) anonymization tool stash [12], in view of Incognito [13], are instances of open-supply toolboxes that give paintings process backing to anonymizing sensitive records. There had been some exceptional endeavours to offer assist for unified questions over diverse records assets via database agency, where there are moreover two stages (community Personal Identifier (PID) and global PID, assortment PID and investigation PID hashes - utilising PKI keys). The identifier (worldwide PID number, examination PID and so on.) is applied to join exclusive research information, tons the same as proper now. The Clinical E-Science framework is every other endeavour to give facts security warranty utilising pseudonymization.

\subsection{Possible questions to be unravelled}

- Can we increase a procedure to element protection necessities and risks to encourage consistence with facts guarantee suggestions?

- How do we gather protection safeguarding cloud-based totally frameworks from existing methodologies in protection and protection?

- How can we increment the wellbeing of an Operating System (OS) with the aid of diminishing the chance of bit abuses?

We propose usable security safeguarding cloud-based systems to process genomics, scientific datasets. For this reason, we contemplated a variety of existing and reducing area look into ventures to recognize the hollow within the field and actualized three structures. The statistics that is put away in these models incorporates facts approximately populace scale genomic statistics, tolerant malignancy information, and cerebrum pictures and henceforth need to verify to security requirements. These systems assure that each one stockpiling and managing of the sensitive data might

be appropriate and might not consist of risks to the safety of the subjects.

\section{BACK GROUND}

As consistent with Vikas [34], there are various safety issues in portable allotted computing. These can be separated into five classes: (1) bodily dangers, which contain flexible belonging and lost or taken gadgets; (2) software-based totally dangers, for instance, those consisting of malware, spyware, protection, and defenseless packages; (three) arrange primarily based portable safety risks, which include Wi-Fi sniffing, forswearing of management, and deal with pantomime; (four) online risks, as an instance, phishing hints, drive-by way of downloads, software endeavours, and jail damaged devices; and (five) different dynamic attacks, including Internet convention vulnerabilities, statistics restoration defencelessness, and unapproved get admission to the board interface.

A distraction resistance system can be conveyed to help the security in numerous situations. [21] Examined some situations wherein an imitation can be utilized. One utilization situation includes utilising an imitation interior a neighbourhood PC, this means that placing the bait report inside a comparable area wherein it changed into made. In some other scenario, the imitation may be situated on a gadget stage. In the 2 situations, the distraction is applied to comfy reviews on various degrees. In any case, a fake can likewise be utilized to ensure programming, as by way of being made to seem as even though a true source code, distraction programming can guard actual programming from unapproved use.

Another distraction usage state of affairs applies a smartphone message bait to distinguish pernicious motion; here the imitation is a true voice message yet contains bogus records. Ultimately, a cloud-based imitation can be applied to make sure reviews in the cloud against insider assaults. A couple of research have focused on ensuring about cloud statistics with the aid of utilising imitation documents. For example, [22] first completed purchaser conduct profiling to decide unapproved get to. At the factor while an assailant receives to the cloud, a fake archive is returned with the give up purpose that the real patron's records are saved relaxed. Each distraction record header contains a shrouded Hash-based Message Authentication Code (HMAC).

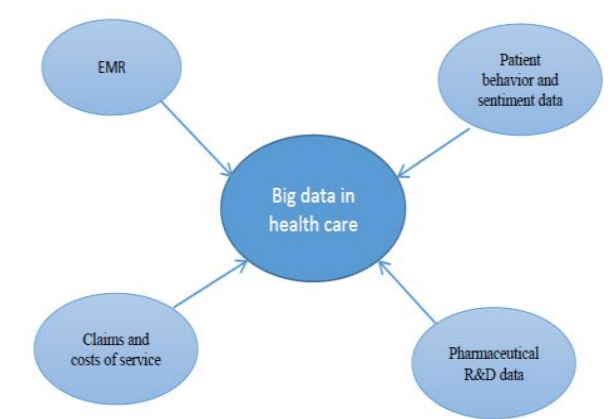

Fig. 1. Big Data Source in Clinical Data

Check of whether or not the report is a distraction is finished with the aid of figuring the HMAC depending on the substance of the archive;
Blue Eyes Intelligence Engineering

\& Sciences Publication

(C) Copyright: All rights reserved.

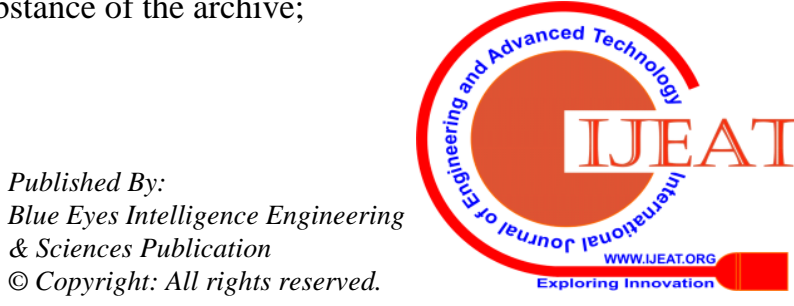


on the off risk that the 2 HMACs coordinate, at that point the report is a faux and an alarm is given. Right now, reviews are utilized for two purposes: first, to approve whether the statistics get to is accredited whilst unusual records get to is identified, and 2nd, to confound the aggressor via giving bogus statistics. It should be observed that solitary bait data are applied right now, those are chosen bodily and covered into the report framework with the aid of the customer. In a comparable technique completed by way of $[3,5]$, malignant insider attacks were forestalled via utilizing fake information innovation. At the factor when anomalous facts get to is prominent, the imitation assists with approving whether the doorway is authorised. Henceforth, whilst unapproved statistics get to is recognized and confirmed, a malevolent internal flood with sham records is come back to weaken the genuine patron records. Likewise, [9] added a way to address cozy distributed computing by using utilizing imitation information. Anomalous information get to designs are recognized through checking the information get to. At the point when unapproved get to is diagnosed and checked, a number of fake statistics is come back to the assailant to defend the genuine facts from any abuse. Such innovation ought to provide uncommon stages of consumer information safety in allotted computing and interpersonal groups too. Further, [7] clarified the approach this is applied to ensure about cloud facts inside the accompanying state of affairs: whilst a client signs in to the framework, a "Successful login" SMS is sent to his/her cellular telephone. The client can execute all errands in the wake of addressing the security question. From that point, certainly one of two specific situations is added: first, if the consumer responds to the inquiry successfully, the first document is downloaded. Second, if the client addresses the inquiry inaccurately, which implies that he/she is an assailant, at that factor the imitation archive is downloaded. At that point, the genuine client receives a SMS containing statistics on the aggressor, for instance, the IP deal with, server call, and get right of entry to date and time, which can be applied to follow the assailant. In $[3,8]$, proposed a $1 / 2$ breed conference that effects on the advantages of encryption and haze figuring to make certain about the cloud from insider attacks. The conference applied a methodology referred to as particular encryption: because of execution troubles, no longer all records can be scrambled, and to address this worry, simply selected statistics that needs more safety is encoded. This is completed with the aid of giving the customer a preference to definitely encode, specifically scramble, or not scramble his/her information by using any stretch of the creativeness. Security and safety problems are amplified by using some parts of Big Data. The normally new huge information instruments were created to manipulate massive arrangements of records. The precept middle within the development became execution and flexibility, on the cost of security. With the improvement of cloud innovation information stockpiling has gotten open and mild for an ever increasing wide variety of gatherings. It gets more diligently to guarantee safety and make certain protection when information is being duplicated and placed away on special servers around the globe. The apparatuses typically applied for Big Data had been gotten out for his or her security shortcomings. A giant variety of the big facts apparatuses were to begin with developed by using huge internet corporations to interrupt down a specific facts. High safety may not generally had been required, since the tool might be a chunk of a bigger programming framework. In the ones cases the safety of these devices depends on outer implementation units gift in the framework. A giant quantity of these instruments shared a regular arrangement of protection holes, inclusive of frail get right of entry to manipulate (confirmation, approval, comparing), shaky correspondences, feeble patron or API protection, no encryption usefulness [11,13].

NoSQL (frequently referred to as Not Only SQL) databases have been recorded as one of the top risks regarding big facts. NoSQL were mainly meant to manage enormous preparations of statistics and efficaciously store unstructured kinds of information, with a constrained accentuation on safety. It has been proven that present NoSQL database bundles simply have a really meagre security layer contrasted with commonplace social database the executive's frameworks (RDBMS). A large lot of those bundles have the safety putting low or are completely handicapped at default. There just a couple NoSQL bundles that meet the information protection requirements [14]. Enormous statistics relies upon massive quantities of modest stockpiling and processing property. Before, Big Data turned into constrained to tremendously large institutions, for example, governments and sizable endeavours that might endure to make and claim the framework critical for facilitating and mining numerous facts. These days, big records stockpiling is affordable and open for greater associations thru open cloud framework. Be that as it could, making use of the cloud as a first-rate component of a primary information association likewise presents security issues all alone. Outstanding problems with the cloud are: facts residency, records encryption, data upkeep and obliteration, and administrative consistence [11] The increasing accessibility of massive informational collections from different sources in blend with the improvement of similarly developed diagnostic devices for large facts makes it an increasing number of tough to guarantee protection. Authorized via law and tenet, associations use strategies as information encryption and facts de-distinguishing proof to guarantee safety. For example, a few protection laws include principles for de-distinguishing evidence that calls for either a expert guarantee that data can't be re-diagnosed using basic real contraptions and rehearses or the evacuation of any records handle that might reason it manageable to re-to differentiate the character $[9,12]$. Associations are using one of a kind de-recognizable evidence procedures like: anonymization, pseudonymization, encryption, key-coding, records sharing, to separate facts from authentic characters and installation their facts for exam even as searching after protection $[8,10]$. Right now will give a few basis data on safety in social coverage. Moreover, this segment will audit enactment recognized with protection in the social coverage. Security is cautiously directed by using enactment and on this way it fundamental research the enactment of safety. Security within the medicinal services worries the records which can be prepared on wellbeing statistics frameworks. Wellbeing statistics frameworks manner the records which can be essential for human offerings forms. Present day protection enactments are for the most component controlling what type

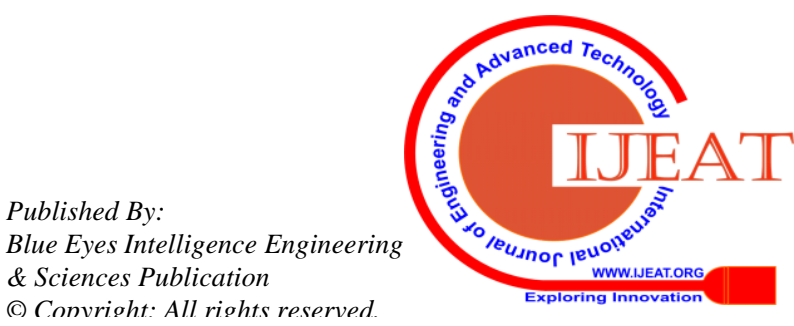


data is viewed as private data and are dealing with which stipulations association want to meet the association is allowed to procedure personal statistics. Notwithstanding, these wellness statistics frameworks incorporate safety sensitive information which contain character statistics and medical information, for instance, Electronic Health Records (EHR). The security delicate attributes of wellness information, requires additional consideration regarding the ability and the managing of such statistics. From the point of view to ensure safety, it's far sizable that wellness statistics stays labelled and publicity of such information simply happens with the patient's assent.

\section{METHODOLOGY}

Members referenced that they discover the country of safety a difficult problem to have a look at about. The member referenced that summary standpoint on this component makes is difficult to talk about. A big part of the members pointed out that the diploma of safety a character encounters is based upon how the man or woman sees it. A few fashions have been given. Members often alluded to a model with online networking. There are folks who display an extensive variety of individual information through web-based networking media, at the same time as others are progressively conscious and saved with the character records they discover. The man or woman concludes a way to manipulate the condition when (personal) statistics is unveiled.

"A few human beings likewise close companions which might be dynamic with safety, are increasingly dynamic and steadily aware of the capability effects that manifest when sure information is unveiled. By and by way of, I am steadily helpful with sharing individual statistics. I don't think there's a massive possibility, that somebody will abuse my personal data. [2]"

This is in a short declaration because it joins two matters together. The assertion delineates the contrasts between how man or woman method the country of safety. Furthermore, it infers that the distinction between the individual methodologies of the state of protection is impacted by using an issue obvious possibility of abuse of individual facts.

Members referenced two styles figuring out with the remark on protection. At one side there is a optimistic pattern, which portrays the eagerness to unveil man or woman statistics. On the other side a gathering of individuals who are increasingly primary closer to, and steadily held in the direction of the revelation of personal records. Table 1 affords an evaluation of the attributes of the wonderful and terrible sample on view of safety.

Members receive that exceptional large a part of the people are motivated via the tremendous sample. More people deliberately display personal records via web-based networking media, yet additionally different administrations, for example, talk administrations. Other than that, individuals are eager to change their personal statistics for gadgets, coins or even just a possibility on a prize. These days, its miles less difficult to steer humans to percentage their private records. Individuals are glad to fill in systems and offer non-public records for a loose example of an object, to get a challenge together with an opportunity to win a car or other considerable prizes, and so on.
It isn't new that humans are changing their own facts for an item or coins, but the scale at which this changing occurs has evolved hugely.

It is through all debts usual in cutting-edge society to share statistics as a superb deal of records is as of now an open, and the huge degree of individuals are willfully uncovering statistics. This might be clarified as a self-improving cycle. In which, extra people are deliberately uncovering person facts, which makes it all of the more publically Figure 2adequate, which at that point invigorates greater people to deliberately unveil individual statistics. Members referenced that maximum of the people do not know approximately the ability effects and therefore are gradually satisfied with uncovering information. The pessimistic sample impacts people which are increasingly simpler and held closer to protection control. They attempt to avoid the equal range of administrations that require a ton of private facts. They are simple towards administrations that require certain data without an unmistakable purpose. This little yet vocal gathering of people esteem private information high. They be given that particular institutions likewise esteem this information high and understand that associations are eager to pay for non-public facts. There look like a commercial enterprise opportunity for this facts.

\section{A.Information access control}

We pointed out what security is in the social insurance element. Security inside the social insurance worries the data which might be treated on well-being records frameworks. Wellbeing statistics frameworks system the records which are fundamental for social coverage forms. The kind of statistics that is prepared on well-being statistics frameworks carries scientific records that is regarded as non-public touchy facts. Undesirable get entry to this non-public information, should set off usage of private information for purposes other than fundamental to the medicinal services forms. Simultaneously medicinal offerings personnel (for instance professionals, attendants) might also want to method scientific statistics placed away within the medicinal services records frameworks. Right now we will give a survey of the statistics get to control writing with regards to the medicinal services. The point of this phase is to bring together records between records get to manipulate and protection within the medicinal offerings. Right now will communicate approximately the maximum well-known get right of entry to control model: the Role Based Access Control (RBAC). Additionally, we can talk approximately from the sooner and a-posteriori get to govern. In the human offerings it's miles trendy to have a crisis get to control framework (a-posteriori) other than a popular get right of entry to control, for example, Role Based Access Control (from the earlier).

\section{B. Role based get admission to control (RBAC)}

The concept of activity based get entry to manipulate (RBAC) has initially been produced to oversee property on multi-purchaser and multi-software on-line framework. The precept concept at the back of RBAC is that get to concur to assets rely on jobs rather than man or woman customers. In view of the extraordinary interest works in the institutions, 
jobs are characterized, and depending on the obligations of the job, the important get right of entry to consent are relegated to the job. RBAC rearranges the administration of authorizations as RBAC allows portrayal of the normal authoritative view upon get to see eye to eye. At the point whilst a client changes work in the affiliation, the consumer can without a whole lot of a stretch be reassigned to other job in inside RBAC, and modifications in authorizations for anybody in a job may be balanced as get right of entry to necessities for capacities inside the institutions are evolving. Because of its prosperity, RBAC has determined its way into several institutions, which includes social insurance associations. In any case, scientists accept that Traditional RBAC isn't reasonable for the medicinal offerings, as customary RBAC frameworks comes up short on the adaptability to manipulate this dynamic condition. [4-8]. Conventional RBAC frameworks depend upon a rule that determine get to rights on an earlier base, via figuring out who (the entertainers) attempts to get to what facts. This guiding principle works high-quality in a static domain, in which the activity of the entertainers related to an front circumstance, is the number one variable. On account of a unique area of the medicinal offerings, the motive for the information access can change relevant respectability of the doorway situation. Logical elements apart from the on-screen characters protected, similar to the motive for the information get right of entry to can legitimize data get to. On account of the human offerings, convenient get admission to to social insurance data can trade the result amongst existence and passing of the patients.

\section{Access control in social coverage}

Conventional get entry to manipulate fashions and preparations rely upon the suspicion that doable get admission to demands that should be obeyed are recognized in advance of time (from the earlier) and may in this manner be caught by using approvals. The human services manages impromptu and dynamic occasions like patients being moved between wards, experts soliciting for $2 \mathrm{~d}$ exams from buddies or essentially spontaneous affected person appearances like crises. Since, the health country of a affected person is prepared (tons) over scientific safety, cases exists that medical facts have to be to be had, in any occasion, while preferred approvals restricts that. As get admission to manage shouldn't meddle with the consideration conveyance in the social insurance, get to govern within the medicinal services frequently include a disaster gadget that sidesteps the usual access strategy that during standard conditions make sure towards unapproved publicity. In the writing, this device is regularly alluded to as "ruin the glass" or quick BtG [20, 24, 26]. While the significance of such aspect to prepare patient's health is self-obvious, this device notwithstanding the whole lot affords shortcomings in the safety of the framework.

[8] Examined the usage of break the glass internal giant Norwegian emergency clinics, with the aid of investigating overview trails from get to logs. Wellbeing facts frameworks are logging get admission to wellness records and contain information to those logs like: time of access, ID of patron (health practitioner, nurture, and so on.) who tries to get to a record, the location of the customer, ID of the patient to which the report has an area with, place of the affected person, and so forth. Also, additional log facts are made while break the glass tool is utilized. Upon a damage the glass demand, the purchaser wishes to go into the rationale behind the damage the glass. The clarification and the hour of solicitation are remembered for the additional break the glass log documents. [8] located in their research that on account of the Norway emergency clinics, that the statistics of fifty four\% of all of the patient enrolled within the wellbeing frameworks have had their clinical statistics been gotten to in any occasion once, via the usage of BtG advantages. From the combination sum of get admission to demands, $17 \%$ of the entrance demands were by BtG benefits. These range suggests that, the utilization of BtG benefits are not utilized as a unique case, but instead a fundamental piece of the contemporary get right of entry to manage method nearly speakme. Perils of such association is that it relies upon plenty on an instrument that permit, unqualified manner which makes area for abuse by means of human offerings representatives [19-25]

\section{D.A-priori as opposed to a-posteriori}

Conventional get right of entry to manage models and strategies depend on the suspicion that practicable get entry to needs that must be obeyed are regarded beforehand of time (from the sooner) and may therefore be stuck through approvals. Approvals are just checked as soon as through a solitary position, for example right now get to is cited.

In the social insurance there is a (spoil-the-glass) system that lets in widespread access manage arrangement that rely on from the sooner to be outdated via a-posteriori get to. Crisis get to ought to be supported utilizing a-posteriori information from log documents that enrolled the entrance. A-posteriori makes greater adaptability, as it permits the clinical team of workers to continue with their obligations, without agonizing over issues like lapse of endorsements, passwords or bombing system availability to some approval server. Figure nine gives a graphical delineation of from the earlier and a-posteriori get to control. Dekker (2007) showed an Audit-Based get admission to manage for the EHR placing that limit from the earlier access manipulate, but middle around a-posteriori manage dependent on evaluate motive.

A considerable necessity for a-posteriori get to manipulate is that there must be a few element installation to assure that clients may be considered liable for their sports, as an example that a patron won't disappear next to executing his (unlawful) sports.

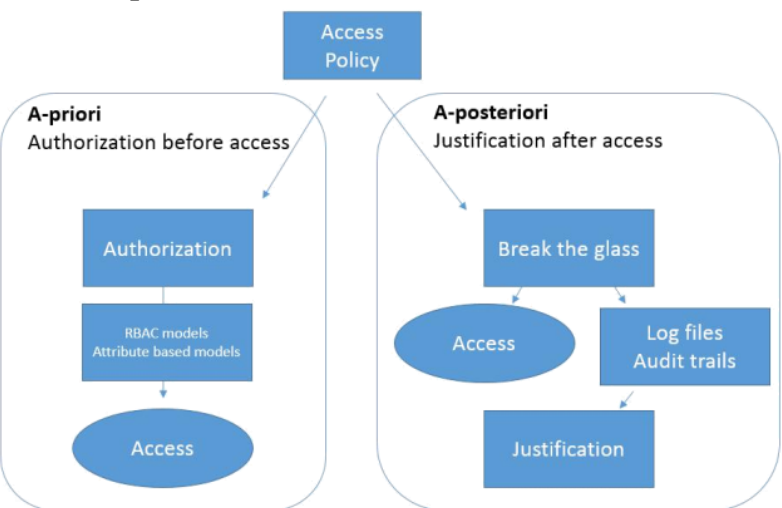

Fig. 2. Access controlling approaches for privacy preserving
Published By:

Blue Eyes Intelligence Engineering \& Sciences Publication

(C) Convriaht: All riahts reserved. 


\section{SPECIFICATION}

That big records in human services region is predominantly approximately incorporating diverse assets in the social coverage. In the association of conferences a few instances of significant records inside the human offerings were given. Three eminent times of massive facts development inside the human offerings that tries to contain several resources in the social insurance. Here we have a look at 3 fundamental instances of huge statistics inside the social insurance referenced by using the individuals, to expand on what large facts implies in the medicinal services. The models deliver step by step strong facts on how substantial information is being applied within the medicinal offerings.

Table I: The main characteristics of the three common in health care.

\begin{tabular}{|c|l|l|l|r|l|}
\hline \multicolumn{2}{|c|}{ Biobanks } & \multicolumn{2}{|c|}{ National EHR } & \multicolumn{2}{|c|}{ Integrated Care } \\
\hline- & $\begin{array}{l}\text { Research } \\
\text { central }\end{array}$ & - & $\begin{array}{l}\text { More } \\
\text { complete } \\
\text { medical }\end{array}$ & $-\begin{array}{l}\text { Patient central } \\
\text { (lifestyle) }\end{array}$ \\
\hline- & $\begin{array}{l}\text { University, } \\
\text { Academic }\end{array}$ & & $\begin{array}{l}\text { History of a } \\
\text { patient. }\end{array}$ & $-\begin{array}{l}\text { Data scattered } \\
\text { among very }\end{array}$ \\
\hline & Hospitals & - & Private data & & diverse group of \\
\hline & $\begin{array}{l}\text { Anonymized } \\
\text { data }\end{array}$ & - & $\begin{array}{l}\text { Data scattered } \\
\text { among }\end{array}$ & $\begin{array}{l}\text { stakeholders in } \\
\text { the health }\end{array}$ \\
\hline & $\begin{array}{l}\text { Standardized } \\
\text { data sets, }\end{array}$ & $\begin{array}{l}\text { stakeholder of } \\
\text { mainly the }\end{array}$ & $\begin{array}{l}\text { Care and social } \\
\text { domain. }\end{array}$ \\
\hline & $\begin{array}{l}\text { with many } \\
\text { instance of the }\end{array}$ & $\begin{array}{l}\text { Health care } \\
\text { domain. }\end{array}$ & $-\begin{array}{l}\text { Type of data: } \\
\text { large variety }\end{array}$ \\
\hline & $\begin{array}{l}\text { same type of } \\
\text { data set }\end{array}$ & & $\begin{array}{l}\text { of data like nurse } \\
\text { reports, }\end{array}$ \\
\hline & $\begin{array}{l}\text { collected from } \\
\text { different }\end{array}$ & & & & Home situations. \\
\hline & People. & & & $-\begin{array}{l}\text { Regulations are } \\
\text { strict }\end{array}$ \\
\hline$-\quad \begin{array}{l}\text { Large volumes of } \\
\text { similar }\end{array}$ & & & & \\
\hline & Data & & & \\
\hline
\end{tabular}

Biobanks are large databases that keep a ton of medical information for check out functions. These biobanks are frequently gift among Universities and Hospitals. Clinical data are collected of big populaces of sufferers, yet moreover of solid people. Instances of clinical statistics placed away in these databases are genome information, genome connection and digestion statistics. The desire is that development of infections can be comprehended.

"For example, in Delft they paintings with (scientific) imaging frameworks. At which good sized volumes of data is being collected about populaces of patients too of solid people. With the usage of this statistics, analysts attempt to create know-how, which could as an example, make forecasts about the advancement of illnesses like: cerebrum infections, Alzheimer, and cardiovascular illnesses. [5]"

"Calculations are being built up that can have a look at singular x-beam pics different styles of imaging-statistics. They are attempting to apply this greater and frequently in emergency clinics. [6]"

Interfacing more bio keeps cash with extra clinical health center and faculties, brings about bigger informational indexes. The gift pattern is to interface extra bio banks and the individual entertainers with each other. This improves statistics sharing among the clinical clinics and the colleges. As result, those bio banks could be bigger as increasingly complete, as greater scientific clinics and colleges save applicable statistics in these bio banks. Figure, offers a schematic diagram of the primary entertainers of a biobanks.

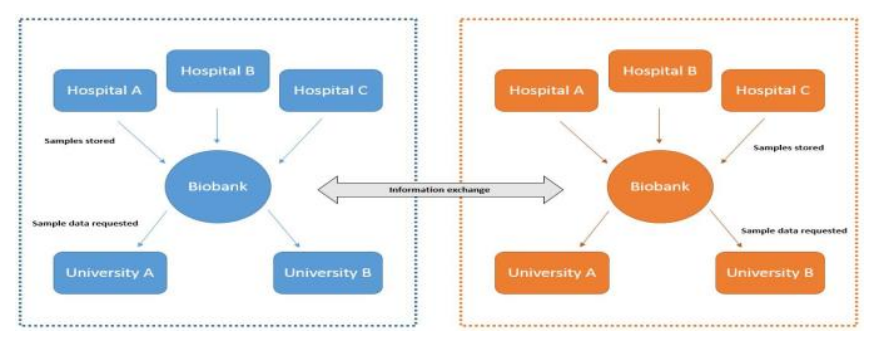

Fig. 3. Biobank divisional data

The theoretical become applied as a shape to arrive at our exploration goal: to research the relationship among massive data and safety. The theoretical version remoted protection I diverse components. These additives of protection have been applied as a guide via the conferences and gave a shape to our exam among protection and massive facts. The components of safety have been mentioned with the contributors and the discoveries from these conversations are delivered right now.

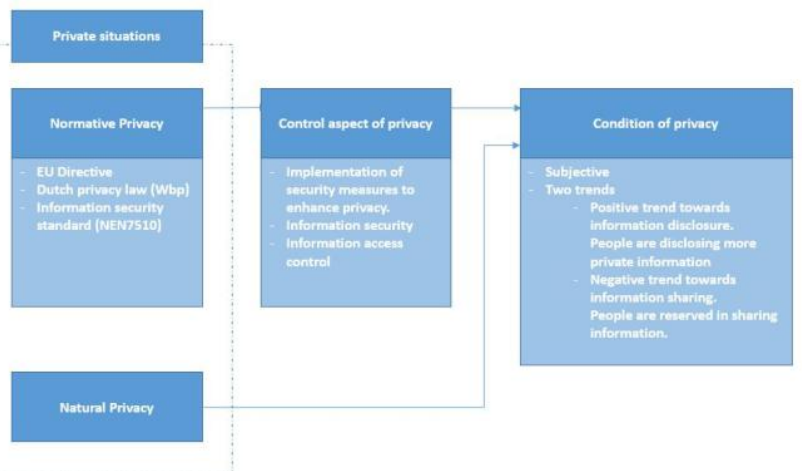

Fig. 4. Privacy Model

All contributors concurred that regular security is diminishing. Large facts is credited as one reason that upload to this sample. Factors, for instance, the increased records age, extended capacity of data, and higher statistics accessibility are clarifications for this. Members additionally alluded to improvements in IT, and modern preparations, as an instance, cloud innovation, data base advancements, advances helping facts the board. One member expressly referenced that common protection doesn't exist any further, as he accepts that advanced society cannot work while there is as yet everyday protection [15-18]. On the off hazard that I relate function protection to the EHR, at that factor I assume that a few humans ought to country that they might choose now not to provide authorization to be remembered for the National EHR foundation, considering certain individuals do not want their personal data to be traded. This goes past the arena we're dwelling in the present second. At a selected minute you visit the medical institution and also you need to be therapeutically dealt with. Clinical facts may be recorded in various records frameworks and are traded. Your blood check will be broke down and the scientific grasp can see this facts on the off danger which you, at that factor say I need protection. How could you envision protection at that point? Do you watched function security no matter the whole lot exists?

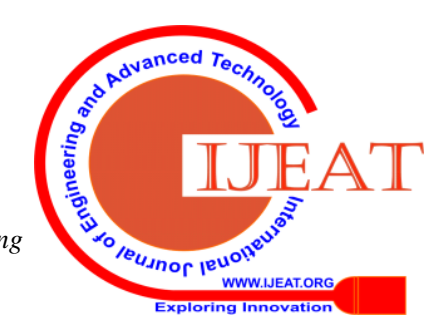


Common protection is a wonder from a global that doesn't exist any further. From the minute an infant is conceived, medical information is recorded. Characteristic safety doesn't exist any longer, on the off threat that you want to utilize the existing benefits of society and want to work appropriately in modern society [1-8]. From a human services point of view this is justifiable. The medicinal services part has constantly been an area that intensely trusted non-public data to work as it should be. This view is meditated in medicinal services regulation, which calls for social coverage people to keep (personal) scientific data of their sufferers. It seems that inside the medicinal offerings element they're applied to the plan to give up function protection for better social insurance.

Despite the fact that ordinary security diminishes due to big statistics, improvements in IT, and innovative preparations, for example, cloud innovation, data base improvements, advances helping statistics the board. Members likewise expressed progressive improvements do enhance our personal circumstance.

Heaps of paper medical facts had been placed on the trash. To query it if that is lots extra cozy. The experience that the prevailing innovation is extra comfortable (for safety), so there is a popularity amongst customers that gift innovation is much less secure (for protection) [21-27].

The electronic stockpiling of clinical records and the association of a framework to share medical facts improve our non-public situation. The principle model gave is that medical statistics used to be recorded on paper. These paper medical records had been put away in chronicles, which took a first-rate deal of room. In positive activities those paper records will be discovered on the trash. As according to a part of the participants this paper stockpiling prompted drastically less sheltered security instances.

4.1.1. Normative safety

All contributors concur that we depend greater on standardizing safety when coping with safety circumstances. The lessening of characteristic protection makes us more relied upon regularizing security. Nonetheless, participants addressed inside the event that it's miles a terrible component that we rely extra on standardizing protection. The diminishing of characteristic security may be important to paintings a slicing area society. A few advantages at cultural degree or a character level can come on the fee of commonplace security. Members referenced that we ought to surrender a part of our individual safety in particular instances, for example, popular wellbeing, battling mental oppression, and the interest of a health facility.

You reserve the choice to hold non-public matters non-public. This could be progressively entangled for statistics this is often viewed as private, however are widespread for well-known health and fighting psychological warfare. I take into account it and I suppose there is an outskirt to what develop personal facts have to maintain private. People have to supply in a few safety for the enthusiasm of most people. Some private information is fundamental for the interest of an emergency health center and maybe for scientific health center personnel. In such case the keenness of the workforce is gradually giant, in particular for virtually undermining instances [8].

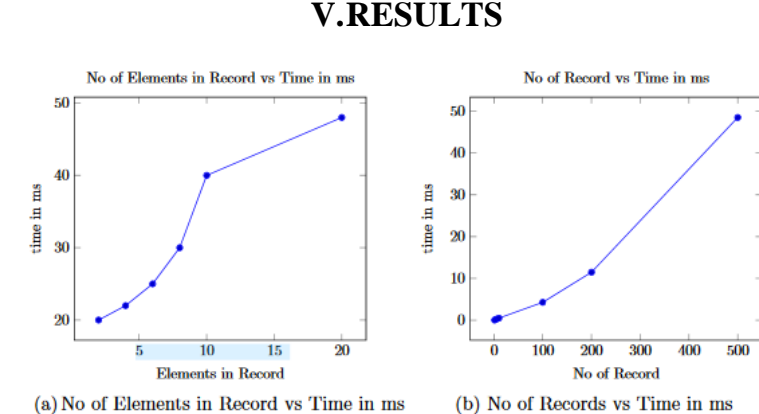

Fig. 5. Peformance graph for Time vs elements of records and No.of records

\section{CONCLUSION \& FUTURE SCOPE}

One of the important thing commitments of this exam is the manufacturing of the applied model of safety, which joined various components of protection in a solitary theoretical model. The calculated model turned into created by joining various speculations from the safety writing: no intrusion hypothesis, the confinement speculation, the manage speculation and the restricted access speculation.

The theoretical model of safety guided this exam to investigate the connection among safety and good sized data within the social coverage section. The theoretical version has tested to be beneficial to break down safety right now including the various components of safety. The various components in the affordable version of safety gave center functions of security to examine about inside the meetings. Thus, we focused on regular safety, regularizing safety and the control part of protection in our meetings.

Another dedication of this examination is the exploratory endeavors on large statistics and safety within the social coverage. The goal of this exam was to accumulate information on protection and protection problems of massive statistics in the human services segment. This investigation brought to the writing by means of social event statistics by means of gathering and breaking down facts from interviews with experts. The discoveries from the meetings tried to reply what the relationship is between massive records and protection inside the medicinal offerings.

One of the restrictions of this exploration is identified with check length of the meetings. At first, it became intended to have at any rate ten members for this exploration. Sadly this become no longer fruitful and the conferences were just led with 8 contributors. This may want to impact the legitimacy of the discoveries of the investigation.

A suggestion for future research is to extend the instance length and increment the growth of encounters of the interviewees.

Another constraint of this exploration is identified with finding that participants experienced problems to deal with addresses identified with records get to control. Troubles in getting valid reactions to the inquiry recognized with statistics get to manipulate should exhibit that the participants remembered for the instance had been now not affordable to deal with the inquiries diagnosed with the facts get to manipulate. Appropriate opportunity to answer records get to govern associated inquiries could be information protection officials, or statistics safety professionals which are 
accountable for the doorway control in the social coverage. Future research ought to collect extra information approximately facts get to control via along with information protection officers, or information security professionals that have involvement with the social insurance.

The quantity of this examination was to satisfy just specialists. A thought for destiny studies is to play out this exam from a customer factor of view (for instance experts, scientific caretakers, patients and so forth.) It may be massive to look to what make bigger the evaluation of clients vary from the checks of the professionals.

\section{REFERENCES}

1. Appari, A., \& Johnson, M. E. (2010). Information security and privacy in healthcare: current state of research. International Journal of Internet and Enterprise Management, 6(4), 279. doi:10.1504/IJIEM.2010.035624

2. Ardagna, C. a., De Capitani di Vimercati, S., Foresti, S., Grandison, T. W., Jajodia, S., \& Samarati, P. (2010). Access control for smarter healthcare using policy spaces. Computers \& Security, 29(8), 848-858. doi:10.1016/j.cose.2010.07.001

3. Azvine, B., Cui, Z., \& Nauck, D. (2005). Towards real-time business intelligence. BT Technology Journal. Retrieved from http://link.springer.com/article/10.1007/s10550-005-0043-0

4. Barth, A., Datta, A., Mitchell, J. C., \& Nissenbaum, H. (2006). Privacy and contextual integrity: framework and applications. 2006 IEEE Symposium on Security and Privacy (S\&P'06), 15 pp.-198. doi:10.1109/SP.2006.32

5. Bhatti, R., \& Grandison, T. (2007). Towards Improved Privacy Policy Coverage in Healthcare Using Policy Refinement, 158-173.

6. Bok, S. (1989). Secrets: On the ethics of concealment and revelation. Random House LLC.

7. Boyd, D., \& Crawford, K. (2012). Critical questions for big data: Provocations for a cultural, technological, and scholarly phenomenon. Information, Communication \& Society, (2012),

8. 662-679. from http://www.tandfonline.com/doi/abs/10.1080/1369118X.2012.67887 8

9. Cattell, R. (2010). Scalable SQL and NoSQL Data Stores, 39(4).

10. Chang, F., Dean, J., Ghemawat, S., Hsieh, W. C., Wallach, D. A., Burrows, M., ... Gruber, R. E. (2008). Bigtable: A distributed storage system for structured data. ACM Transactions on Computer Systems (TOCS), 26(2), 4.

11. Chen, H., Chiang, R., \& Storey, V. (2012). Business Intelligence and Analytics: From Big Data to Big Impact. MIS Quarterly, 36(4), 1165-1188. Retrieved from http://scholar.google.com/scholar?hl=en\&btnG=Search\&q=intitle:BU SINESS+INTELLIGE

NCE+AND+A+NALYTICS:+FROM+BIG+DATA+TO+BIG+IMPA CT\#0

12. Cloud Security Alliance. (2013). Expanded Top Ten Big Data Security and Privacy Challenges, (April).

13. Decandia, G., Hastorun, D., Jampani, M., Kakulapati, G., Lakshman, A., Pilchin, A., ... Vogels, W. (2007). Dynamo: amazon's highly available key-value store. ACM SIGOPS ..., 205-220. Retrieved from http://dl.acm.org/citation.cfm?id=1294281

14. Dekker, M. a. C., \& Etalle, S. (2007). Audit-Based Access Control for Electronic Health Records. Electronic Notes in Theoretical Computer Science, 168(1), 221-236. doi:10.1016/j.entcs.2006.08.028

15. Elbashir, M., Collier, P., \& Davern, M. (2008). Measuring the effects of business intelligence systems: The relationship between business process and organizational performance. International Journal of Accounting Information Systems, 9(3), 135-153. doi:10.1016/j.accinf.2008.03.001

16. Fidelis Cybersecurity Solutions. (2014). Current Data Security Issues of NoSQL Databases.

17. Forsman, S. (1997). OLAP Council white paper. OLAP Council.

18. Fried, C. (1984). Philosophical dimensions of privacy: An anthology. (F. D. Schoeman, Ed.).

19. Cambridge University Press.

20. Gavison, R. (1980a). Privacy and the Limits of Law. Yale Law Journal, 89(3), 421-471. Retrieved from http://www.jstor.org/stable/795891

21. Gavison, R. (1980b). Privacy and the Limits of Law. Yale Law Journal, 89(3), 421-471.
22. Gens, F. (2012). TOP 10 PREDICTIONS IDC Predictions 2012 Competing for 2020, (December 2011).

23. Google. (2011). Google Flu Trends. Retrieved from http:/ www. google. org/ flutrends/ about/ how.html

24. Groves, P., \& Knott, D. (2013). The " big data " revolution in healthcare, (January).

25. Hamami, O. (2011). Big Data Security: Understanding the Risks, 19(2), 20-27.

26. Han, J. (1997). OLAP mining: An integration of OLAP with data mining. In Proceedings of the 7th IFIP (Vol. 2, pp. 1-9).

27. Himma, K., \& Tavani, H. (2008). The handbook of information and computer ethics. (K. Himma \& H. Tavani, Eds.). Retrieved from http://books.google.com/books?hl=en\&lr=\&id=ZC7SDyPZUMoC\&o $\mathrm{i}=$ fnd \&pg $=$ PR7\&dq $=\mathrm{T}$

$\mathrm{HE}+\mathrm{HANDBOOK}+\mathrm{OF}+\mathrm{INFORMATION}+$ and+computer+ethics\&ots =lca-BbB153\&sig=I1Rxi-IYvq0ulFs9tm6G5I0KSl0

28. Khan, R. A., \& Quadri, S. M. K. (2012). Business intelligence: an integrated approac. Business Intelligence Journal, 5(1), 64-70.

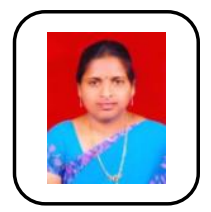

\section{AUTHORS PROFILE}

MadhaviLatha Pandala working as Assistant Professor in Department of IT Since 12 Years. Interested Areas are Data Mining, Machine Learning

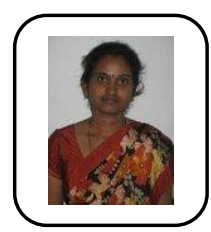

Madhavi Katamneni working as Assistant Professor in Department of IT Since 12 Years. Interested Areas are Data Engineering

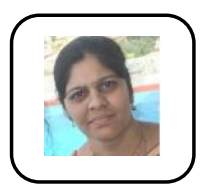

Praveena Nutakki working as Assistant Professor in Department of IT Since 12 Years. Interested Areas are Cloud Computing, Networking, Data Engineering

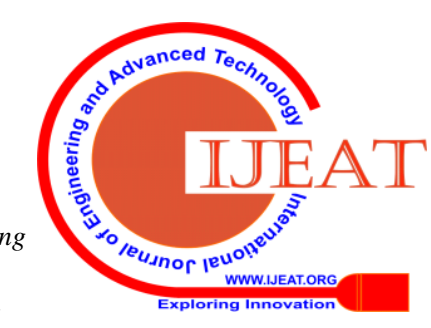

